\title{
A experiência de arquivamento intermediário em escritórios de advocacia de Belo Horizonte, na ótica da gestão de documentos: estudo de casos múltiplos
}

Nilcéia Lage de Medeiros

Mestre em Administração pela Faculdade Novos Horizontes. Especialista em Gestão de Arquivos e Documentos pelo IEC da Pontifícia Universidade Católica de Minas Gerais (PUCMinas).

Leandro Ribeiro Negreiros

Mestre em Ciência da Informação pelo Programa de Pós-Graduação da Escola de Ciência da Informação da Universidade Federal de Minas Gerais (UFMG). Professor Assistente do Curso de Arquivologia da UFMG. Bibliotecário da Assembleia Legislativa de Minas Gerais (ALMG).

Cléia Márcia Gomes do Amaral
Mestre em Ciência da Informação pelo Programa de Pós-Graduação da Escola de Ciência da Informação da Universidade Federal de Minas Gerais (UFMG). Professora titular dos cursos de Ciência da Informação e Sistema de Informação da Pontifícia Universidade Católica de Minas Gerais (PUCMinas).

A pesquisa descreve e discute os critérios de transferência para depósitos intermediários, de documentos administrativos e processuais em três escritórios de advocacia de Belo Horizonte, sob a ótica da gestão de documentos. Os resultados revelaram que os problemas de espaço foram preponderantes na decisão relativa à transferência para da documentação para espaços fora das dependências dos escritórios, sendo adotadas as seguintes alternativas: arquivamento de processos em depósito não localizado na área nobre da cidade e de propriedade do escritório; "arquivo morto" para arquivamento de processos em sala situada na área central da cidade e de propriedade do escritório; depósito para guarda terceirizada dos documentos dos setores de Recursos Humanos e de Contabilidade/Financeiro. O que se observou foi que a decisão de adoção de espaços para 
depósitos intermediários, onde o $\mathrm{m}^{2}$ é mais barato, não teve como referencial o ciclo vital dos documentos. Neste sentido desconsideraram-se os benefícios trazidos pela adoção da sistemática da avaliação. Observa-se que os três escritórios de advocacia estão diante de uma produção de documentos que cresce sem planejamento/gestão/avaliação e que tende a alcançar grande volume.

Palavras-chave: Arquivos intermediários; Gestão de documentos.

\section{The semi-current records filing experience in three law offices in Belo Horizonte, from the viewpoint of document management: multiple case} study

The study describes and discusses the criteria for transfer of administrative documents and legal processes to agency records centers in three law offices in Belo Horizonte, from the viewpoint of document management. The results showed that space problems were prevalent in deciding the transfer the documentation to spaces outside the office premises.The following alternatives were adopted: archival storage of legal processes outside the downtown area and owned by the office; archival storage of legal processes, such as a deposit, in a room located in the downtown area and owned by the office; outsourced warehouse for the storage of Human Resources and Accounting / Finance documents. It was observed that the decision for adoption of spaces for an agency records center, where the rent per square meter is cheaper, did not have the life cycle of documents as a reference. In this sense, the benefits brought by the adoption of systematic evaluation was overlooked. It is observed that the three law firms are facing a growing production of documents without planning / management / evaluation, and that documentation tends to reach a high volume.

Keywords: Agency records centre; Document management.

Recebido em 01. 03. 2010 Aceito em 01.06.2011 


\section{Introdução}

Em um cenário de novas tecnologias da informação e da comunicação, assistimos, ainda, à geração e ao arquivamento de grandes massas de documentos em papel. Seja pelo hábito ou legislação brasileira vigente, o documento em papel ainda é uma realidade que convive simultaneamente com documentos digitais. Uma das áreas que também se depara com a produção, reprodução e acumulação acelerada e indiscriminada de papéis é a jurídica.

O Judiciário enfrenta sérios problemas trazidos pelo armazenamento de enormes massas documentais: situação caótica e insustentável de crescimento vertiginoso; recursos escassos para o tratamento técnico adequado; e exorbitantes volumes financeiros aplicados de maneira indiscriminada e injustificada, com a guarda e manutenção de documentos com pouca ou nenhuma sistematização e segurança, onerando os cofres públicos e o contribuinte (BRASIL. Conselho da Justiça Federal, 2003; BRASIL. Supremo Tribunal Federal, 2003; JUSTIÇA..., 2002; SÃO PAULO. Tribunal de Justiça, 1999).

Esse problema tem diversos fatores agravantes, entre os quais se destacam: número elevado de recursos disponíveis na legislação processual $^{1}$; excessivo prazo de prescrição dos documentos; enorme quantidade de textos legais obsoletos, que elevam o número de ações na Justiça; e inexistência de espaço físico para se continuar guardando a extensa produção crescente de papel que circula pelo Judiciário ${ }^{2}$ (BRASIL. Supremo Tribunal Federal, 2003; ENTULHO..., 2010; SÃO PAULO. Tribunal de Justiça, 1999).

É nesse contexto documental jurídico que se insere o processo judicial, resultado de toda atividade jurisdicional, que, ao longo do trâmite, pode atingir grande volume (SANTOS, 2006), agravando o problema de processos arquivados no Judiciário, de crescimento exponencial. Isso acaba por abarrotar os tribunais com arquivos ineficazes em relação aos instrumentos de controle, pesquisa e acesso ${ }^{3}$, bem como tempo hábil para desarquivamento. Registrem-se, também, os orçamentos gigantescos gastos na manutenção de arquivos, não afastando, ainda, o perigo iminente causado pela ausência ou ineficiência dos procedimentos para conservação e preservação dos documentos, com resultados danosos e ineficazes. Em muitos casos, esses arquivos são vistos como depósitos de papéis velhos, que dificultam o acesso ao seu conteúdo, privando juízes, servidores e cidadãos do direito à informação e

${ }^{1} \mathrm{O}$ advogado e professor Moacyr Caram Júnior informa que ações/processos judiciais na área civil podem ter até 40 recursos diferentes, uma quantidade que retarda as execuções (PARA AGILIZAR..., 2009).

${ }^{2}$ Outros fatores: disposição da lei processual, não admitindo que se promova uma execução sem os autos principais/primitivos; ações incidentais; e recursos referentes a um processo que, sem o devido tratamento técnico, não podem ser localizados juntos, uma vez que ações principais, seus recursos e ações incidentes não são arquivados em conjunto.

3 "Documento recolhido, guardado e não organizado significa inexistência de informação" (ROSA, 2008). 
de outros direitos que decorrem do uso de documentos como prova documental (BRASIL. Conselho da Justiça Federal, 2003; BRASIL. Supremo Tribunal Federal, 2003; MIRANDA, 2007).

Nesse caso, são utilizadas medidas, tais como a transferência de documentos para arquivos centrais ou fora do prédio da administração ${ }^{4}, 0$ que remete a uma questão já abordada por Rosseau e Couture (1998, p. $120,127)$ :

Os organismos são forçados a admitir, mais cedo ou mais tarde, que o armazenamento de documentos pouco utilizados, em locais mais apropriados e que oferecem uma densidade de armazenamento mais elevada do que nos escritórios, constitui uma prática que proporciona vantagens inequívocas [...]

Nos casos em que a quantidade de documentos é restrita, o senso comum permite não ter em conta o período [...] de semi-atividade que só existe por razões de economia de espaço e dinheiro, economias que só são realizáveis se as quantidades o justificarem.

Diante do exposto, o arquivo intermediário é, pois, um novo elemento $^{5}$, trazido pela Teoria das Três Idades, que é utilizado e disseminado na gestão de documentos, sendo conhecido como segunda idade do ciclo vital dos documentos: uma extensão da idade corrente, um período transitório que, ao fazer cumprir a Tabela de Temporalidade e Destinação de Documentos (TTDD), principal instrumento de controle de documentos de um sistema de arquivos, leva a redução da documentação a proporções manipuláveis.

Assim, a prática arquivística sente os reflexos da escassez de recursos e da necessária utilização eficaz e eficiente dos recursos informacionais. Ela também não está imune da necessidade de administração racional e econômica. Tudo isso aponta para a necessidade de maior eficiência, de racionalização do trabalho arquivístico e de melhor aproveitamento dos recursos humanos e materiais na gestão adequada dos documentos processuais e administrativos em arquivos, tanto públicos como privados. Desse modo, é mister que haja uma gestão de documentos, intervindo nas três fases de vida dos documentos - corrente,

\footnotetext{
${ }^{4}$ Vale ressaltar que a experiência de envio de processos para fora das dependências do TJSP se mostrou ineficaz e foi denunciada e repudiada por vários advogados por conta do tempo gasto no desarquivamento de processos, dando indícios de que foi realizado sem o devido tratamento técnico nas idades documentais (avaliação, classificação, descrição...), caracterizando-se um depósito de papéis (A INUMAÇÃO..., 2005). Há de se ter em mente, que nada deve ser enviado para o arquivo intermediário sem o devido tratamento e a determinação da temporalidade.

5 Novo elemento expresso na teoria arquivística, mas que, acredita-se aqui, acompanha a humanidade. Veja, por exemplo, o hábito de se guardar, em pleno verão, as roupas de inverno em lugares diferentes (blusas de frios mais volumosas). Isso liberaria espaço para aquisições de roupas da moda e facilitaria, por exemplo, a guarda de roupas mais utilizadas, que poderiam ser amarrotadas caso o armário estivesse cheio. É possível até que seja estipulado um critério: que as blusas de frio não utilizadas por três invernos seguidos sejam doadas. Isso corresponde à mesma lógica de arquivamento temporário.
} 
intermediária e permanente - objetivando possibilitar: comprovação de direitos dos cidadãos; preservação de documentos que retratem a cultura, o conhecimento e a história; apoio aos processos de tomada de decisão; e disponibilização de instrumentos de pesquisa que levem a resultados relevantes.

Nesse sentido, surge a curiosidade científica que norteou esta pesquisa: será que escritórios de advocacia, que são parte do sistema judiciário nacional, resguardadas as devidas proporções, caminham na mesma direção contextual aqui apresentada para o Poder Público, em relação à acumulação e ao arquivamento dos documentos?

Discutir, sob a ótica da gestão de documentos, os critérios adotados para arquivamento intermediário dos documentos em escritórios de advocacia, foi considerado o objetivo geral desse trabalho. Como objetivos específicos propuseram-se: a) Investigar os fatores que levaram à utilização de arquivamento intermediário nos escritórios de advocacia; b) Identificar os critérios adotados para a utilização de arquivamento intermediário em escritórios de advocacia; e c) Descrever as alternativas adotadas para arquivamento intermediário em escritórios de advocacia.

\section{Referencial teórico}

Na literatura nacional, esse período transitório de guarda intermediária por tempo pré-determinado, para que seja dada a destinação final aos documentos, tem as seguintes terminologias: arquivos intermediários, semiativos, semicorrentes; centros intermediários de documentos; pré-arquivo; idade intermediária / $2^{a}$ idade; ciclo intermediário / 20 ciclo; fase intermediária; limbo / purgatório; e depósitos intermediários.

O arquivamento intermediário é um serviço de apoio administrativo de retenção temporária, por um tempo pré-estabelecido, com menor custo e segundo métodos apropriados, tanto para prever circunstâncias de emergência (órgãos extintos, suprimidos ou desativados...) como para aliviar os arquivos dos documentos que ainda dispõem de valor administrativo, legal, jurídico e fiscal, embora sem potencial de uso frequente e que, por isso, não precisam mais ser conservados próximos às unidades produtoras, assegurando a preservação e a conservação física e cumprindo os prazos estipulados na TTDD (incluídos os de retenção, de prescrição, de precaução), administrando o fluxo, até que seja dada a destinação final, reduzindo de forma racional e criteriosa a massa de documentos (COSTA, 2006; ESPOSEL, 1994; INDOLFO, 2007; LINARES, 2007; MACHADO; CAMARGO, 1999; VIEIRA, 2001).

As abordagens sobre os problemas de espaços cada vez mais exíguos em locais administrativos e a necessidade de racionalização administrativa, de economia e de otimização de recursos, em relação ao arquivamento de documentos, levaram à necessidade de promover a avaliação de documentos e a consequente criação dos arquivos intermediários (NúÑEZ FERNÁNDEZ, 1999; ROUSSEAU; COUTURE, 1998; 
VIEIRA, 2001). Assim, são descritas as suas características: deverão localizar-se, de preferência, fora da empresa, em imóveis e bairros menos valorizados, situados nos arredores dos grandes centros e de fácil acesso às administrações; construções e instalações de baixo custo e manutenção barata, primando pela simplicidade (uso de materiais e equipamento, simples e de baixo custo $^{6}$ ); o número estritamente necessário de servidores; as dimensões devem ser fixadas em função da massa de papéis a receber e da previsão de crescimento; devem possuir de $5 \%$ a $10 \%$ de superfície para trabalho e o restante para depósitos; as paredes devem ser privadas de aberturas ou com aberturas pouco numerosas e pequenas, protegendo os documentos da luz solar nos arquivos; e a propriedade da documentação continua a ser da administração que a acumulou (BRASIL. Ministério da Justiça, 1985; CASTRO; CASTRO; GASPARIAN, 1988; GARCIA; FÉ, 2008; LOPES, 1996; MACHADO; CAMARGO, 1999; PAES, 2006).

Apresentam-se na literatura as funções, atividades e consequentes vantagens dos arquivos intermediários:

a) receber os documentos que passaram por cuidadoso processo de avaliação e valoração nos arquivos nas repartições ${ }^{7}$, e submetê-los às TTDD, fazendo-se cumprir os prazos estipulados para o trânsito dos documentos até a destinação final, assegurando que nenhum documento seja conservado por tempo maior do que o necessário para 0 cumprimento das atividades que o geraram;

b) evitar a destruição descontrolada, salvando arquivos guardados em porões, debaixo das escadas que podem ser objeto de faxina, permitindo uma política de conservação/preservação dos arquivos;

c) racionalizar as eliminações de forma controlada, reduzindo seletivamente a proporções manipuláveis e evitando a formação de massas de documentos volumosas, evitando que os arquivos intermediários se transformem em meros depósitos de papel sem valor;

d) reduzir os custos ao assegurar simplicidade e facilidades na guarda e conservação dos documentos, fazendo com que os arquivos intermediários atinjam seu objetivo principal - a economia - de espaço, pessoal, equipamentos e tempo;

e) atender a consultas feitas por órgãos depositantes;

\footnotetext{
${ }^{6}$ Vale ressaltar que a economia almejada com arquivos intermediários não dispensa a utilização de recursos de qualidade para a conservação e preservação de documentos. Para isso, indicamos, entre outros, os trabalhos publicados no "Projeto CPBA". Disponível em: $<$ http://143.106.151.46/cpba/prj_pub.htm>. Acesso em: 2 fev. 2010.

7 "É junto das administrações, na fase de produção da informação, que é preciso intervir. [...]. Só uma intervenção nesta fase poderá estancar o crescimento desmesurado e descontrolado [...] e evitará os 'arquivos intermédios' em situações como a nossa [...]" (RIBEIRO, 2004).
} 
f) empregar suporte mais resistente para os documentos de valor permanente e os de maior demanda de uso; e

g) arquivar temporariamente a documentação de catástrofes, órgãos extintos, suprimidos ou desativados (BRASIL. Ministério da Justiça, 1985; CASTRO; CASTRO; GASPARIAN, 1988; CONTINOLO, 1975; COSTA, 2006; ESPOSEL, 1994; JARDIM, 1987; LÓPEZ GÓMEZ; GALLEGO DOMÍNGUEZ, 2007; PAES, 2006).

Vale ressaltar que os pontos apresentados fazem parte de uma situação desejável, mas bem se sabe que, na realidade, os arquivos correntes, intermediários e permanentes passam por extremas dificuldades, aproximando-os, muitas vezes, do indesejável.

\section{Metodologia}

Os arquivos de escritórios de advocacia são, efetivamente, pouco pesquisados. Assim, buscou-se obter informações, na percepção dos respondentes que atuam nesses escritórios, que auxiliem na compreensão e descrição dos critérios adotados para arquivamento intermediário de documentos de caráter arquivístico (administrativos e processuais), em escritórios de advocacia de Belo Horizonte, sob a ótica da gestão de documentos.

Utilizou-se o método de estudo de casos múltiplos ${ }^{8}$, para realizar o aprofundamento de determinado fenômeno contemporâneo que não esteja claramente definido e evidente em um dado contexto real de unidade social.

Nesta pesquisa, os critérios para a seleção da unidade de observação foram: escritórios sediados em Belo Horizonte/MG, tomandose por base a acessibilidade, o tempo e os custos da pesquisa; e escritórios que, além de utilizarem o arquivamento de documentos em suas dependências, optaram pelo arquivamento de documentos fora de suas dependências.

Foi construído um questionário constituído de perguntas abertas, fechadas e de múltipla escolha, para captar explicações e interpretações capazes de auxiliar a identificação das variáveis para a compreensão dos fenômenos na perspectiva dos sujeitos. As perguntas foram categorizadas em 12 seções, abaixo descritas, e buscavam caracterizar os arquivos e trazer elementos para possibilitar a descrição e análise da lógica de arquivamento intermediário adotada pelos escritórios. São elas:

\footnotetext{
${ }^{8}$ Casos múltiplos não podem ser vistos como unidades amostrais, pois correspondem a diversas fontes de evidência e experimentos (YIN, 2006). Assim, não se pretende impor a existência de um escritório/arquivo como modelo mais adequado para a avaliação da experiência de arquivamento intermediário, e, sim, apresentar a variabilidade em sua expressão empírica.
} 
a) na identificação, buscou-se obter a metragem do escritório, se está em área nobre de Belo Horizonte, e a quantidade de pessoal;

b) na massa de documentos, o ano de início do acervo arquivístico e a sua quantificação ${ }^{9}$;

c) na terceira seção, buscou-se identificar os tipos de setores para arquivamento de documentos utilizados pelo escritório, sendo disponibilizadas as seguintes opções: "próximo dos funcionários, setoriais, central e, por fim, arquivo/depósito fora das dependências da empresa (próprio ou terceirizado)";

d) na quarta seção intitulada "arquivos", buscou-se identificar a área total gasta no escritório com arquivamento, opinião sobre o espaço ainda disponível para arquivamento no escritório, formas de acondicionamento da documentação arquivada, se possui arquivo deslizante, número de funcionários e respectivo grau de instrução e, por fim, cargo e formação do responsável pelas decisões ligadas ao arquivo;

e) na quinta seção, os respondentes deveriam marcar, entre as opções disponíveis, as cinco atividades mais importantes desenvolvidas/executadas no arquivo do escritório;

f) nas seções de 6 a 9, foram abordados aspectos sobre atividades de transferência de documentos que ficavam juntos/próximos dos profissionais, eliminação, microfilmagem e digitalização;

g) na seção 10, buscou-se verificar se o escritório possuía gerenciamento eletrônico de documentos (GED);

h) na seção 11 , buscou-se a opinião dos respondentes sobre 0 fato de as decisões relativas aos arquivos serem baseadas preponderantemente em gestão administrativa, gestão documental ou gestão de informações/conhecimento;

i) na seção 12 , buscava-se o motivo mais preponderante para a existência das funções exercidas em relação ao arquivo foram indicados diversos motivos impossibilitando a detecção do mais preponderante, por isso essa seção foi desprezada.

Para a seleção, foi consultada a publicação Análise Advocacia (2008), selecionando-se todos os 47 escritórios sediados em Belo Horizonte.

Com o resultado em mãos, optou-se pelo envio do questionário via correio, solicitando que cooperassem com a pesquisa, obtendo-se, até 30 de novembro de 2009, resposta de quatro escritórios - a unidade de

\footnotetext{
${ }^{9}$ Não houve padronização na indicação da quantificação do acervo arquivístico, levando esse dado a ser desprezado. Optou-se, então, por indicar somente o espaço gasto para arquivamento no escritório (Pergunta 4).
} 
observação, por conta dos critérios estabelecidos, foi composta de três ${ }^{10}$. A troca de e-mails com os respondentes foi a opção utilizada para obter os esclarecimentos adicionais que se fizeram necessários.

Foi escolhida a técnica de análise de conteúdo, visando identificar, interpretar e descrever o que foi dito e percebido sobre o tema.

\section{Apresentação e análise dos resultados}

Os escritórios que responderam ao questionário e concomitantemente atenderam os critérios de seleção serão tratados, a partir desta seção, por "A", "B" e "C". Todos estão no mercado há pelo menos duas décadas, sendo que " $C$ " iniciou-se em 1981. Possuem entre 31 e 50 funcionários, com exceção de " $B$ ", que possui mais de 100. Estão situados em área nobre de Belo Horizonte, ocupando de 600 a $1000 \mathrm{~m}^{2}$, sendo que " $C$ " possui maior tempo de existência, o de maior metragem $\left(1.000 \mathrm{~m}^{2}\right)$.

a) Foram encontradas as seguintes opções de arquivamento nos três escritórios:

b) arquivos que ficam próximos a funcionários, situados em salas, estantes etc. - uma das opções de arquivamento adotadas por "B" e "C";

c) arquivos setoriais para recursos humanos $(\mathrm{RH})$ e contabilidade/financeiro, geridos exclusivamente pelos dois setores, encontrados em " $A$ " $e$ " $C$ ";

d) arquivo central para o arquivamento dos processos, nas dependências dos três escritórios analisados;

e) depósito não localizado na área nobre de Belo Horizonte, de propriedade de "A", para arquivamento de processos;

f) "arquivo morto" para arquivamento de processos situado em uma sala de $40 \mathrm{~m}^{2}$, de propriedade de " $\mathrm{C}^{\prime}$, situada na área central de Belo Horizonte e fora de sua instalação administrativa do escritório; e

g) depósito, fora das dependências de "B", para guarda terceirizada dos documentos dos setores de $\mathrm{RH} e$ contabilidade/financeiro ${ }^{11}$.

Pode-se notar que não existe uma única opção de arquivamento adotada nos três escritórios. Isso confirma o que já foi dito sobre o fato de

${ }^{10} \mathrm{O}$ arquivamento intermediário será tratado na perspectiva do terceiro ciclo documental apresentada por Lodolini (1995 citado por NÚÑEZ FERNÁNDEZ, 1999), não englobando o arquivo central (segundo ciclo).

11 Será que só foram enviados documentos pouco utilizados ou com baixo potencial de uso? Caso contrário, há que se avaliar o preço e o tempo gasto no trânsito de documentos, que são utilizados com maior frequência. 
a lógica de arquivamento temporário ser inerente ao ser humano, e não uma criação da teoria arquivística (ver nota número 5). A maior colaboração da Teoria das Três Idades, para que os arquivos cumpram sua função de apoiar as atividades gerenciais, em um ambiente de produção crescente de documentos, consiste em dar subsídios à necessária e adequada avaliação e conservação de documentos. Isso levará à determinação do trânsito do documento até a destinação final, promovendo, principalmente, a redução controlada e criteriosa da massa de documentos.

O espaço gasto com arquivamento no interior desses escritórios é de $5 \%$ para " $C$ " e de $20 \%$ para " $A$ " e "B". " $A$ ", "B" e "C", que utilizam arquivos deslizantes, adotados com o objetivo de arquivar maiores quantidades em menor espaço físico, já iniciaram a digitalização de processos $^{12}$ e declararam que estão se precavendo, para que não ocorra falta de espaço para arquivamento no escritório. ${ }^{13}$

O número de pessoas lotadas/disponibilizadas para atuar com arquivos nos escritórios é o seguinte:

a) no " $A$ ", são 4, sendo uma bibliotecária formada na Universidade Federal de Minas Gerais (UFMG), uma consultora formada em Biblioteconomia e atualmente professora no curso de Arquivologia da UFMG, duas estagiárias que cursam Biblioteconomia na UFMG e, ainda, um profissional terceirizado, que foi indicado via e-mail;

b) no "B", dez, sendo 8 advogados que exercem a função de paralegal ${ }^{14}$, uma arquivista terceirizada e uma pessoa que exerce a função de serviços gerais;

c) no "C", são três, que exercem a função de auxiliar de escritório, não sendo indicados os níveis de instrução.

Os escritórios " $A$ " e " $B$ " são os únicos que informaram ter em suas equipes profissionais especializados para o arquivo. Sabendo-se, de antemão, que a UFMG formará a primeira turma de graduados em Arquivologia, em dezembro de 2012, e que a PUC Minas formou a segunda turma no curso de especialização em Gestão de Arquivos e

12 Ressalta-se que a falta de foco na gestão de documentos pode mudar o problema de m2 para bits, salientando-se que a preservação de documentos digitais passa pela fragilidade, perecibilidade e rápida obsolescência, que são ameaças constantes para a perda de acesso aos acervos digitais (VALLE JR., 2003).

13 O escritório que utiliza menos espaço administrativo para arquivamento é "C" - ele possui arquivos deslizantes, utiliza depósito próprio para arquivamento onde o $\mathrm{m} 2$ é menos valorizado, e começou a digitalização de processos.

Não há informações sobre a quantidade de documentos digitalizados, metragem dos depósitos fora das dependências dos escritórios e do espaço terceirizado gastos por " $A$ " e " $B$ ", não sendo possível informar, por esse motivo, qual dos dois realmente utiliza maior espaço de arquivamento.

14 Paralegal - são advogados formados que, além da prestação de serviços a clientes em cartórios, também dão suporte às atividades legais dos escritórios de advocacia, por meio da prestação de diversos serviços internos, como pesquisas etc. (LEITE, 2006). 
Documentos, em 2009, há que se estudar as opções disponíveis no mercado mineiro, para o treinamento dos profissionais incumbidos dos arquivos.

As atividades ${ }^{15}$ desenvolvidas e executadas no arquivo do escritório são: definição de tipos documentais, formatação e padronização de documentos ("B"); definição de fluxos documentais/controle e tramitação dos documentos (" $A$ "); recebimento/protocolo/expedição (" $B$ "); registro de documentos (" $A$ " e "B"); empréstimo ("B"); classificação/ordenação do arquivo (definição de classes para arquivamento (" $A$ " e "B"); arquivamento (" $A$ ", " $B$ " e " $C$ "); atendimento a pesquisas (" $A$ "); e digitalização de documentos (" $A$ ").

Vale ressaltar que indexação (determinação de assuntos), confecção de instrumentos de pesquisa (catálogos, listas, inventários) e avaliação e seleção não foram determinadas por nenhum dos entrevistados. ${ }^{16}$

As decisões ligadas ao arquivo são de responsabilidade de advogados que exercem o cargo de sócios em " $B$ "; gerente, no " $A$ "; e administrador, no " $C$ ". Em " $A$ ", as decisões são tomadas pelo gerente, em conjunto com a bibliotecária.

Há que se ressaltar que as decisões sobre os prazos de vida dos documentos devem ser tomadas por uma comissão destinada a esse fim. Infelizmente, os dados coletados vão de encontro ao indicado na literatura. Dessa forma, ressaltamos que uma decisão que afeta toda a organização e é de grande responsabilidade, não deveria ser tomada por um único profissional e, sim, por equipes multidisciplinares.

A microfilmagem" ${ }^{17}$ foi utilizada por " $B$ ", sendo 0 motivo preponderante a falta de espaço. Já a digitalização vem sendo efetuada diariamente em " $A$ " $e$, paulatinamente, em " $B$ " e " $C$ ", sendo motivada pela falta de espaço nos três. O escritório " $C$ " informou que já está iniciando a digitalização dos documentos que estão no "arquivo morto". ${ }^{18}$ Houve eliminação de papel, após o procedimento nos três escritórios. ${ }^{19}$

Vale ressaltar que a opção por reprodução em outros suportes sem identificação e avaliação configura investimento inútil quando incide sobre documentos desprovidos de valor e sem o devido tratamento técnico arquivístico (BRASIL. Conselho da Justiça Federal, 2003).

A transferência da documentação de perto dos funcionários para outro local aconteceu nos três escritórios (seja para o arquivo central e/ou

\footnotetext{
${ }^{15}$ Foram solicitadas apenas cinco, os escritórios " $A$ " e " $\mathrm{B}$ " indicaram seis, e o " $\mathrm{C}$ " apenas um (o arquivamento).

${ }^{16} \mathrm{O}$ primeiro, talvez por haver uma linha que acredita que não se faz indexação em arquivos. 0 segundo, talvez por acreditar que no arquivamento eletrônico seja feito automaticamente. 0 terceiro, uma linha acredita que isso não seja tarefa a ser executada pelo arquivista.

17 Há que se avaliar se a opção de microfilmagem tem relação com a validade jurídica ou se era a única opção no passado.

18 Se está no "arquivo morto", por que digitalizar?

19 A utilização de mídias para a redução do volume da documentação por meio da mudança de suporte, por exemplo, a microfilmagem ou a digitalização, que trazem, entre outros benefícios, a redução de espaço e a agilidade na recuperação e no acesso, as quais são vistas como paliativas por Santos (2006), quando desprovidas de critérios de avaliação, que se traduzem na TTDD. Concorda-se aqui, com a posição do autor.
} 
para arquivo da própria empresa ou terceirizado localizado em área onde o $\mathrm{m}^{2}$ é menos valorizado) e foi motivada pela falta de espaço conforme " $A$ " e "B", e também pelo ganho no armazenamento denso e centralizado por " $C$ ". A utilização de arquivo central foi unanimidade nos três escritórios. Apuraram-se, depósitos de propriedade em " $A$ " e " $C$ ", e guarda em depósito terceirizado fora da empresa em "B". A periodicidade é irregular em " $A$ " $e$ " $B$ " e não existem documentos que regulem tal atividade em "B".

Vale ressaltar que receber bem os documentos, ou seja, em bom estado de conservação, com as respectivas TTDD, o plano de classificação etc., é condição sine qua non para que os arquivos intermediários possam trazer a economia e não se transformem em meros depósitos de papel sem valor.

Nos três escritórios, já ocorreram eliminações e foram assim descritas:

a) "A", "B" e " $C$ ", indicaram as seguintes causas para as eliminações: documentos velhos, cópias, falta de espaço e digitalização;

b) os documentos são triturados em "B", incinerados em "B" $\mathrm{e}$ " $C$ ", devolvidos a clientes por " $B$ " e " $C$ ", e utilizados como rascunho e depois picotados em " $\mathrm{A}$ ";

c) apenas " $C$ " possui normas para a eliminação, o que talvez explique a regularidade com que ela aconteça, ao contrário dos demais escritórios, que não possuem normas e indicam a periodicidade irregular para as eliminações;

d) "B" e "C' fazem listagem do que foi eliminado;

e) os responsáveis pelas decisões ligadas ao arquivo aprovam formalmente as eliminações em " $A$ " e " $B$ ", ao passo que " $C$ ", segue as determinações contidas nas normas do arquivo; $e$

f) todos os respondentes informaram que a documentação eliminada estava organizada.

A urgência na liberação de espaços físicos leva, em muitos casos, à decisão de eliminar documentos. Há que se ressaltar o extremo perigo, quando a eliminação não é baseada em critérios de avaliação, que se traduzem na TTDD, já que impede definitivamente o acesso aos documentos.

Outros pontos que merecem reflexões:

a) a destruição de documentos, após a digitalização, deve levar em conta a legislação nacional, já que ela ainda não 
reconhece em muitos casos20, ao contrário da microfilmagem, a validade jurídica do documento digital;

b) utilização de trituramento, incineração e devolução de documentos a clientes estão previstas em contrato com o cliente ou segue, nos dois primeiros casos, o estipulado pelo mercado, em prol do sigilo da informação?; e

c) as cópias são indícios da falta de gestão de documentos?

Em relação às decisões relativas aos arquivos do escritório, para "C", baseiam-se preponderantemente na racionalização/eficácia na gestão administrativa do escritório; para " $A$ " e "B", na racionalização da gestão da informação/conhecimento. Tais visões podem ser melhor compreendidas se confrontadas com o grau de instrução do pessoal que atua nos arquivos e principais atividades exercidas. Em " $\mathrm{B}$ " $\mathrm{e}$ " $\mathrm{C}$ ", recursos humanos mais qualificados e as atividades indicadas poderão levar à gestão adequada de documentos nos arquivos. Confrontadas com a literatura arquivística, tais decisões têm a válvula propulsora para a adoção de arquivos intermediários, ou seja, custos e espaço físico. Mas, será que a decisão, os critérios e as opções podem ser vistas no âmago da gestão de documentos? Vejamos a seguir.

\subsection{Análise dos casos frente aos objetivos específicos}

\subsubsection{Investigar os fatores que levaram à utilização de arquivamento intermediários nos escritórios de advocacia}

Os profissionais formados em advocacia são os responsáveis pelas decisões relativas aos arquivos em todos os três escritórios (no " $A$ ", advogado e a bibliotecária tomam as decisões em conjunto).

Foram indicados os seguintes fatores para a utilização de arquivamento intermediário nos escritórios de advocacia (QUADRO 1):

QUADRO 1 - Fatores indicados para a utilização de arquivamento intermediário nos escritórios de advocacia

\begin{tabular}{|l|l|l|l|}
\hline $\begin{array}{c}\text { Fatores que levaram escritórios à utilização de } \\
\text { arquivamento intermediário }\end{array}$ & $\mathrm{A}$ & $\mathrm{B}$ & $\mathrm{C}$ \\
\hline Falta de espaço & $\mathrm{X}$ & $\mathrm{X}$ & \\
\hline Ganho no armazenamento denso e centralizado & & & $\mathrm{X}$ \\
\hline
\end{tabular}

Fonte: Dados da pesquisa.

\footnotetext{
20 Vale ressaltar que, com a Medida Provisória no. 2.200-2/2001, "houve reconhecimento legal expresso do uso de assinaturas digitais por processo criptográfico para atribuir autenticidade e integridade a documentos eletrônicos" (GRANDE, 2009).
} 
Tal como apontado na literatura arquivística e na apresentação dos problemas enfrentados pelo Judiciário, " $A$ " $e$ " $B$ " disseram que foram motivados a utilizar espaços para arquivamento de documentos fora do escritório, devido a problemas de espaço cada vez mais exíguo em locais administrativos (NúÑEZ FERNÁNDEZ, 1999; ROUSSEAU; COUTURE, 1998; VIEIRA, 2001): são razões práticas, de agilidade, imediatismo e economia (SILVA et al.,1999). Sob esse aspecto, se o objetivo é somente a liberação de espaço físico onde o $\mathrm{m}^{2}$ é mais caro, os resultados foram alcançados.

Já " $C$ " disse que foi motivado pelos ganhos advindos do armazenamento denso e centralizado, o que não é possível afirmar que alcance esse intento, já que o dito "arquivo morto" é descrito na literatura como um limbo ou depósito, um perigo para a conservação do que realmente precisa ser mantido e um desperdício de recursos com o que pode ser eliminado (BRASIL. Conselho da Justiça Federal, 2003). ${ }^{21}$ Percebe-se aqui, que a razão preponderante é a liberação de espaço em locais administrativos.

Os dados analisados vão ao encontro da literatura, quando indicam que a falta de espaço físico nas áreas administrativas foram preponderantes à decisão de arquivamento intermediário. Porém, vão de encontro à literatura, se levarmos em conta que as necessidades de economia de recursos foram preponderantes à decisão de arquivamento intermediário. Há indícios fortes de utilização do arquivo intermediário adotado como depósito, ou seja, acumulação indiscriminada de documentos, que não foram avaliados e podem não ter valor primário e secundário e nem potencial de uso.

Lodolini (1995 citado por NúÑEZ FERNÁNDEZ, 1999) afirma que os arquivos intermediários são uma reação dos sistemas arquivísticos diante do crescimento geométrico da produção e acumulação da documentação, da impossibilidade de se conservar tudo; e da necessidade de intervenção dos arquivistas na organização e gestão dos fundos mediante técnicas de gestão de documentos. Diante disso, não é possível afirmar que tal reação, sob a ótica da gestão de documentos, tenha sido a válvula propulsora que levou os três escritórios a arquivarem documentos em locais situados fora da área nobre.

21 Depósito de papéis - são documentos acumulados indiscriminadamente e sem critérios, reflexo também da inexistência de avaliação (valoração documental) nas idades documentais. 


\subsubsection{Identificar os critérios adotados para a utilização de arquivamento intermediário em escritórios de advocacia}

Foram adotados dois critérios para o arquivamento de documentos fora das dependências administrativas dos escritórios (QUADRO 2):

a) Documentos dos setores RH e Contabilidade/Financeiro;

b) Processos.

QUADRO 2 - Critérios adotados pelos escritórios para a utilização de arquivamento intermediário fora das dependências administrativas

\begin{tabular}{|c|c|c|c|}
\hline $\begin{array}{c}\text { Critérios adotados pelos escritórios para a utilização de arquivamento intermediário } \\
\text { fora das dependências administrativas }\end{array}$ & A & B & $\mathrm{C}$ \\
\hline \multicolumn{4}{|l|}{ Processos } \\
\hline de propriedade do escritório não localizado na área nobre de Belo Horizonte & $\mathrm{X}$ & & \\
\hline de propriedade do escritório localizado na área central de Belo Horizonte & & & $\mathrm{X}$ \\
\hline \multicolumn{4}{|l|}{ RH e contabilidade/financeiro } \\
\hline guarda terceirizada & & $\mathrm{X}$ & \\
\hline
\end{tabular}

Fonte: Dados da pesquisa.

A literatura já indicava que as áreas de $\mathrm{RH} e$ Contabilidade/Financeira, utilizam a opção de arquivamento intermediário, principalmente pela quantidade de documentos gerados e pelos longos prazos de prescrição determinados na legislação. Nesse caso, há que se analisar se os documentos enviados são muito utilizados pelos setores. Em caso afirmativo, os custos relativos ao trânsito do intermediário para esses setores não poderá ser uma opção antieconômica para a empresa. Além disso, a empresa também deverá ter acesso a esses documentos, que estão previamente organizados, em tempo hábil para comprovação, tomadas de decisão, etc. Por fim, há que se ressaltar que os prazos para destinação final deverão estar pré-determinados. Caso contrário, essa documentação irá crescer indeterminadamente, acompanhada pelo aumento de custos, mesmo que mais reduzidos por conta da opção de arquivamento intermediário.

Em relação aos processos, há que se analisar, primeiramente, a denominação de "arquivo morto", o que pode dar a impressão de um depósito que crescerá indiscriminadamente, guardando "papéis velhos", que não têm valor e nem potencial de uso. Nesse caso, a opção pelo arquivamento fora das dependências administrativas iria se configurar como um desperdício de recursos. Seria apenas um isolamento do problema, levando-o para outro endereço.

Acredita-se que há indícios fortes de que não há intervenção no ciclo de vida dos documentos e parece haver um espírito de concentração de documentos em papel. Estaria Indolfo (2007, p. 55) longe de entender o espírito dos advogados, quando afirma que "nem tudo que é produzido fica registrado e nem ficará conservado definitivamente"? 


\subsubsection{Alternativas adotadas para o arquivamento temporário em escritórios de advocacia}

As alternativas adotadas para o arquivamento intermediário, excetuando-se os arquivos centrais, foram (QUADRO 3):

a) " $A$ " - depósito não localizado na área nobre de Belo Horizonte, de sua propriedade, para arquivamento de processos;

b) B" - depósito, fora de suas dependências, para guarda terceirizada dos documentos dos setores de $\mathrm{RH} e$ Contabilidade/Financeiro; e

c) "C" - "arquivo morto" para arquivamento de processos, situado em uma sala de $40 \mathrm{~m}^{2}$, de sua propriedade, na área central de Belo Horizonte, e fora de sua instalação administrativa.

QUADRO 3 - Alternativas adotadas pelos escritórios para o arquivamento intermediário (excetuando-se os arquivos centrais)

\begin{tabular}{|c|c|c|c|}
\hline $\begin{array}{l}\text { Alter nativ as adotadas pelos escritórios para o arquivamento intermediário } \\
\text { (excetuando-se os arquivos centrais) }\end{array}$ & A & B & $\mathrm{C}$ \\
\hline \multicolumn{4}{|l|}{ Fora da dependência administr ativa - de propriedade do escritório } \\
\hline Não localizado na área nobre de Belo Horizonte - processos & $\mathrm{X}$ & & \\
\hline $\begin{array}{l}\text { Localizado em área central de Belo Horizonte em uma sala de } 40 \mathrm{~m}^{2}- \\
\text { "arquivo morto" de processos }\end{array}$ & & & $\mathrm{X}$ \\
\hline \multicolumn{4}{|l|}{ Fora da depend ência administrativa - terceirizado } \\
\hline Guarda terceirizada - $\mathrm{RH}$ e contabilidade/ financeiro & & $\mathrm{X}$ & \\
\hline
\end{tabular}

Fonte: Dados da pesquisa.

Tais alternativas de arquivamento de documentos em locais fora da área nobre, onde o escritório está situado, seja de propriedade ou terceirizado, poderiam ser vistas como de arquivamento intermediário.

Acredita-se aqui, tomando-se por base a gestão de documentos, que tais alternativas são opções administrativas do escritório, e não uma opção arquivística de intervenção no ciclo de vida dos documentos, por meio da opção pelo arquivamento intermediário, com tempo predeterminado para que seja dada a destinação final.

\section{Considerações finais}

O objetivo principal desta pesquisa - discutir os critérios de arquivamento intermediário de documentos nos escritórios de advocacia, sob a ótica da gestão de documentos - foi alcançado. O que se observou, sem a intenção de se fazer generalizações, foi que a decisão de adoção de espaços para arquivamento de documentos onde $0 \mathrm{~m}^{2}$ é mais barato, não 
quer dizer que foi calcada na intervenção do ciclo vital dos documentos, não alcançando, assim, a plenitude dos benefícios trazidos pela adoção da sistemática da avaliação e do arquivamento intermediário, sob a ótica da gestão de documentos.

Os problemas do Judiciário, apresentados na pesquisa, guardadas as devidas proporções, também foram identificados, aqui e ali, nos arquivos dos escritórios de advocacia. Dentre eles, destacam-se: falta de normas, manuais e instrumentos de pesquisa e de gestão de documentos; documentos sem prazos de guarda, o que caracteriza um depósito de papéis - são documentos acumulados indiscriminadamente e sem critérios, reflexo, também, da inexistência de avaliação nas idades documentais; espaços físicos insuficientes; falta de recursos humanos, tanto em número como em qualificação; e urgência na liberação de espaços físicos, levando, em muitos casos, à decisão de eliminar documentos sem critérios ou reprodução em outros suportes, sem identificação e avaliação, o que, neste último caso, configura investimento inútil, quando incide sobre documentos desprovidos de valor e sem 0 devido tratamento técnico arquivístico (BRASIL. Conselho da Justiça Federal, 2003).

Tomando-se por base o crescimento indiscriminado da documentação e a necessidade de avaliação, seleção, tratamento e conservação da massa de documentos, reduzida seletivamente a proporções manipuláveis, para que o arquivo seja um apoio à eficiência administrativa, o caminho ainda é longo e requer: racionalizar e definir critérios para o fluxo da produção de documentos (exceto " $A$ "); definir e utilizar normas, manuais e instrumentos que embasem a gestão de documentos $^{22}$; submeter os documentos às TTDD, procedendo à triagem/seleção, de acordo com os prazos de vida estipulados e fazendo com que transitem até a sua destinação final ${ }^{23}$; reduzir a proporções manipuláveis a massa de documentos, de forma controlada e criteriosa, incrementando a pesquisa e promovendo a agilidade na recuperação de informações e documentos, na busca da eficiência administrativa; utilizar recursos humanos qualificados e em número suficiente (ausentes em " $\mathrm{C}^{\prime \prime}$ ); assegurar simplicidade e facilidades na guarda e conservação dos documentos, proporcionando à administração economia considerável de espaço, pessoal, equipamentos e tempo nos arquivos temporários ${ }^{24}$ (BRASIL. Ministério da Justiça, 1985; CASTRO; CASTRO; GASPARIAN, 1988; CONTINOLO, 1975; COSTA, 2006; ESPOSEL, 1994; JARDIM, 1987; LÓPEZ GÓMEZ; GALLEGO DOMÍNGUEZ, 2007; PAES, 2006).

${ }^{22}$ Buscar a redução de incertezas nas destinações, na destruição e na acumulação indiscriminada e descontrolada de documentos nas fases de vida.

${ }^{23}$ Vale salientar a importância da avaliação e da consequente definição do prazo de vida dos processos, principalmente os que estão no "arquivo morto", para que não haja desperdício de recursos na guarda ou na opção pela troca de suporte, esta última já vem sendo realizada por "A", "B" e "C".

${ }^{24}$ Há que se ter bem claro o significado da fase intermediária na gestão de documentos - não se pretende criar depósitos que acumulem, indiscriminadamente, a crescente massa de documentos. 
Conclui-se que, tal como o contexto apresentado para o setor público, os três escritórios de advocacia analisados, ocupam $\mathrm{m}^{2}$ valorizados, estão diante de uma produção de documentos que cresce sem planejamento/gestão/avaliação e que tende a alcançar grande volume. Assim, os escritórios de advocacia, que são parte do sistema judiciário nacional, caminham na mesma direção do setor público, em relação a lógica de acumulação e arquivamento dos documentos em papel. Em síntese, os dados apresentados, analisados sob a ótica da gestão de documentos, indicam a necessidade de maior eficiência e racionalização do trabalho arquivístico nos três escritórios de advocacia.

A opção pelo arquivamento intermediário, por meio da disponibilização de espaços físicos nobres para a administração, permite a melhor utilização onde $0 \mathrm{~m}^{2}$ é mais caro. Porém, a intervenção no ciclo de vida dos documentos e, quando necessária, a opção pelo arquivamento intermediário vão além: requer a determinação de um caminho, determinado por um processo avaliativo, para que o documento transite até a sua destinação final. Esse é o caminho que levará os três escritórios a usufruírem, com eficácia e eficiência, dos ganhos com a racionalização administrativa, economia e otimização de recursos advindos da opção pelo arquivamento intermediário, sob a ótica da gestão de documentos, e que são indicados na literatura (NÚÑEZ FERNÁNDEZ, 1999; ROUSSEAU; COUTURE, 1998; VIEIRA, 2001). Salienta-se que a liberação de espaço em área nobre sem que haja avaliação e nem TTDD, não faz valer o preconizado pelo Arquivo Nacional (BRASIL. Ministério da Justiça, 1993; 2001): nenhum documento deverá ser conservado por tempo maior do que o necessário, para o cumprimento das atividades que o geraram.

Por fim, acredita-se, aqui, que conhecer e divulgar a realidade vivida pelos escritórios de advocacia possa auxiliar na conscientização da importância da gestão de documentos na área jurídica, o que poderá levar a um melhor planejamento e sintonia de atividades relacionadas à gestão racional de arquivos entre o setor público e o privado. Nesse contexto de racionalidade, encontra-se o cerne da avaliação e do arquivo intermediário. Espera-se que esta pesquisa traga informações e leve a reflexões que auxiliem na compreensão dos adequados procedimentos e benefícios, diante da adoção da lógica presente no arquivamento intermediário e na gestão de documentos a todos os interessados.

Como reflexão para pesquisas futuras, acredita-se que há indícios fortes de que não havendo intervenção no ciclo de vida dos documentos em papel não houve e nem haverá gestão de documentos na massa de documentos que foi microfilmada ("B"), nem na que está sendo digitalizada ou na que já nasce digital ("A", "B" e "C").

\section{Referências}

ANÁLISE Advocacia. Rio de Janeiro: Analise Editorial, 2008.

BRASIL. Conselho da Justiça Federal. Comissão Técnica Interdisciplinar para Gestão de Documentos. Proposta de critérios de seleção de autos 
findos para a preservação da memória nacional. R. CEJ, Brasília, n. 21, p. 68-75, abr./jun. 2003.2 Disponível em: <http://www.cjf.jus.br/revista/numero21/artigo11.pdf>. Acesso em: 2 fev. 2010.

BRASIL. Ministério da Justiça. Arquivo Nacional. Gestão de documentos: conceitos e procedimentos básicos. Rio de Janeiro: Arquivo Nacional, 1993. (Série Publicações Técnicas, n. 47).

BRASIL. Ministério da Justiça. Arquivo Nacional. Conselho Nacional de Arquivos. Classificação, temporalidade e destinação de documentos de arquivo: relativos às atividades meio da administração pública. Rio de Janeiro: CONARQ, 2001.

BRASIL. Ministério da Justiça. Arquivo Nacional. Orientação para avaliação e arquivamento intermediário em arquivos públicos. Rio de Janeiro: Arquivo Nacional, 1985. (Série Publicações Técnicas, Técnica, 41).

BRASIL. Supremo Tribunal Federal. ADIN no 1.919-8-SP. Rel. Min. Ellen Gracie. DJ, 1으 ago. 2003. Disponível em: <www.stf.jus.br>. Acesso em: 2 fev. 2010.

CASTRO, Á. M.; CASTRO, A. M.; GASPARIAN, D. M. C. Arquivística arquivologia: arquivística = técnica, arquivologia = ciência. Rio de Janeiro: Ao Livro Técnico, 1988.

CONTINOLO, G. Como organizar o arquivo. 2. ed. São Paulo: Martins Fontes, [1975].

COSTA, L. C. Arquivologia: série questões comentadas. Brasília: FDK, 2006.

ENTULHO de um milhão de leis dificulta a vida dos brasileiros. Brasil Econômico, 13 jan. 2010.

ESPOSEL, J. P. Arquivos: uma questão de ordem. Niterói: Muiraquitã, 1994.

GARCIA, G. A.; FÉ, T. M. Noções de arquivologia. Brasília: Fortium, 2008.

GRANDE, Paulo Vestim. Medida Provisória 2.200-2 de 24 de agosto de 2001. 18 mar. 2009. Disponível em: <http://www.grande.adv.br/node/9>. Acesso em: 2 fev. 2010.

INDOLFO, A. C. Gestão de documentos: uma renovação epistemológica no universo da arquivologia. Arquivistica. net, Rio de Janeiro, v. 3, n. 2, p. 28-60, jul./dez. $2007 . \quad$ Disponível em: <http://www.arquivistica.net/ojs/viewarticle.php?id=155>. Acesso em: 2 fev. 2010.

A INUMAÇÃO do arquivo morto. Migalhas, 12 jul. 2005. Disponível em: $<$ http://www.migalhas.com.br/mostra noticia.aspx?cod=13777>. Acesso em: 2 fev. 2010.

JARDIM, J. M. O conceito e a prática de gestão de documentos. Acervo, Rio de Janeiro, v. 2, n. 2, p. 35-42, 1987. Disponível em: 
$<$ www.cid.unb.br/.../m\%F3dulo4-

OConceitoePr\%E1ticaGest\%E3oDocumentos.doc>. Acesso em: 2 fev. 2010.

JUSTIÇA paulista é proibida de queimar processos arquivados. Conjur, 19 abr. 2002. Disponível em: <http://www.conjur.com.br/2002-abr19/stj proibe justica queimar processos arquivados $>$. Acesso em: 2 fev. 2010.

LEITE, F. O que é um paralegal? 2006. Disponível em: <http://www.infonet.com.br/faustoleite/ler.asp?id=43298\&titulo=Fausto Leite $>$.

Acesso em: 2 fev. 2010.

LINARES, A. P. A descrição no departamento archivo intermedio. Acervo, Rio de Janeiro, v. 20, n. 1/2, p. 67-76, jan./dez. 2007.

LODOLINI, E. Archivística: principios y problemas. Salamanca: ANABAD, 1995 citado por NÚÑEZ FERNÁNDEZ, E. Organización y gestión de archivos. Astúrias: Trea, 1999.

LOPES, L. C. A Informação e os arquivos: teorias e práticas. Niterói: EDUFF; São Carlos: EDUFSCar, 1996.

LÓPEZ GÓMEZ, P.; GALLEGO DOMÍNGUEZ, O. El documento de archivo: um estúdio. Coruña: Universidade da Coruña, 2007. (Monografias, n. 126).

MACHADO, H. C.; CAMARGO, A. M. A. Como implantar arquivos públicos municipais. São Paulo: Arquivo do Estado, 1999. (Como fazer, n. 3). Disponível

em:

<http://www.arquivoestado.sp.gov.br/saesp/texto pdf 12 Como\%20implantar\%20ar quivos\%20publicos\%20municipais.pdf>. Acesso em: 2 fev. 2010.

MIRANDA, M. P. S. A atuação do Ministério Público na defesa do patrimônio arquivístico sob a guarda do Poder Judiciário. O problema da eliminação e do acesso aos autos processuais findos. Jus Navigandi, Teresina, v. 11, n. 1583, 1 nov. 2007. Disponível em: <http://jus.uol.com.br/revista/texto/10597/a-atuacao-do-ministeriopublico-na-defesa-do-patrimonio-arquivistico-sob-a-guarda-do-poderjudiciario>. Acesso em: 2 fev. 2010.

NÚÑEZ FERNÁNDEZ, E. Organización y gestión de archivos. Astúrias: Trea, 1999.

PAES, M. L. Arquivo: teoria e prática. 3. ed., rev. e ampl. Rio de Janeiro: FGV, 2006.

PARA AGILIZAR a Justiça, Código de Processo Civil terá reforma. 16 out. 2009. Disponível

em:

<http://www.senado.gov.br/sf/senado/novocpc/detalha noticias.asp?codigo=69077

>. Acesso em: 2 fev. 2010.

RIBEIRO, F. Sem gestão de informação não há memória que perdure... 21 jan. 2004. Disponível em: <http://ciencia-dainformacao.blogspot.com/2004_01_01_archive.html>. Acesso em: 2 fev. 2010. 
ROSA, V. L. O valor do arquivo organizado para a gestão do conhecimento em entidades públicas e privadas. Tubarão, 2008. Disponível em: $<$ http://portal2.unisul.br/content/navitacontent /userFiles/File/noticias/ed itais 2008/artigo vera.doc >. Acesso em: 2 fev. 2010.

ROUSSEAU, J-Y.; COUTURE, C. Os fundamentos da disciplina arquivística. Lisboa: Dom Quixote, 1998.

SANTOS, M. J. A doação de processos judiciais findos: uma abordagem arquivística e legal. Arquivística.net, Rio de Janeiro, v. 2, n. 2, p. 157-171, jan./jun. $2006 . \quad$ Disponível em: $<$ http://www.arquivistica.net/ojs/include/getdoc. php?id=296\&article=65\&mode=pdf $>$. Acesso em: 2 fev. 2010.

SÃO PAULO. Tribunal de Justiça. $3^{a}$ Vice-Presidência. Mandado de Segurança no 40.689-0/6. Presidente: Oetterer Guedes. Relator: Álvaro Lazzarini. Julgamento: 30 set. 1998. Disponível em: <http://esaj.tj.sp.gov.br/cjsg/resultadoCompleta.do>. Acesso em: 2 fev. 2010.

SILVA, A. M. et al. Arquivística: teoria de uma ciência da informação. 2. ed. Porto: Edições Aforamento, 1999.

VALLE JR., E. A. Sistemas de informação multimídia na preservação de acervos permanentes. Disponível em: $<$ http://www.arquivar.com.br/espaco profissional/sala leitura/teses-dissertacoes-e>. Acesso em: 2 fev. 2010.

VIEIRA, S. B. Técnicas de arquivo e controle de documentos. Rio de Janeiro: Temas \& Idéias, 2001.

YIN, R. K. Estudo de caso: planejamento e métodos. 3. ed. São Paulo: Bookman, 2006. 